\title{
Helium irradiation effects on deuterium retention in tungsten
}

\author{
Y. Sakoi ${ }^{1}$, M. Miyamoto ${ }^{1 *}$, K. Ono ${ }^{1}$ and M. Sakamoto ${ }^{2}$ \\ ${ }^{1}$ Department of Material Science, Shimane University, Matsue, Shimane 690-8504 Japan \\ ${ }^{2}$ Plasma Research Center, University of Tsukuba, Tsukuba, Ibaraki 305-8571 Japan
}

\begin{abstract}
To investigate effects of helium irradiation on deuterium retention properties in tungsten, thermal desorption spectroscopy of deuterium from a specimen irradiated with a sequential irradiation of $3 \mathrm{keV}$ helium and $1.5 \mathrm{keV}$ deuterium ions at room temperature was measured and the related microstructure was observed by transmission electron microscopy. It was found that pre-irradiation of $3 \mathrm{keV} \mathrm{He}^{+}$ions to fluences of $1.0 \times 10^{21}-1.0 \times 10^{22} \mathrm{He}^{+} / \mathrm{m}^{2}$ increased, while the retention of deuterium drastically decreased above the fluences of $1.0 \times 10^{23} \mathrm{He}^{+} / \mathrm{m}^{2}$. A similar reduction of deuterium retention was also observed by the pre-exposure of the specimen to a very low energy ( $10 \mathrm{eV})$ and high fluence helium plasma. The reduction effects on deuterium retention are discussed in terms of the formation of linked or interconnected structure of bubbles, which could create an easy release and diffusion path for deuterium desorption.
\end{abstract}

\section{Introduction}

Tungsten (W) is one of the most important candidate materials for a plasma facing device in the ITER divertor because of its high melting temperature, high thermal conductivity, and low sputtering erosion yield [1]. In the ITER DT (deuterium-tritium) phase, the W plasma facing device will be exposed to burning plasma of high density helium (He) and hydrogen isotopes. Behavior of hydrogen isotopes in $\mathrm{W}$ is a very important problem because of its influence on plasma operation parameters via re-emission of hydrogen isotopes. Therefore, to simulate effects of burning plasma, several studies on hydrogen isotope retention and surface erosion in W have been reported using ion beams [2-4] and linear plasma simulators [5,6]. Recently, a significant reduction in deuterium retention due to seeding of helium into deuterium plasma has been reported $[7,8]$ and some related microstructures have been clarified [9]. However, the operative mechanism of helium-vacancy 
complexes or bubbles formed near the specimen surface in relation to deuterium retention is not clear in detail, and systematic experimental data obtained using controlled irradiation are required.

In this study, therefore, sequential irradiation of helium and deuterium ions was performed by changing the order of ion species and fluence, and the retention of deuterium was measured by thermal desorption spectroscopy (TDS).

\section{Experimental procedure}

The material used in this study was $99.95 \%$ nominal purity W supplied by Nilaco Corp. A sheet-shaped specimen $0.1 \mathrm{~mm}$ thick was cut into a $10 \times 10 \mathrm{~mm}^{2}$ rectangle and annealed at $1473 \mathrm{~K}$ for $0.5 \mathrm{~h}$ to release internal stresses. Electrochemical polishing and ultrasonic cleaning of the specimen were performed prior to irradiation.

To examine the effects of helium ion irradiation on the deuterium trapping, sequential ion irradiation of the specimen was performed by changing the order of the ion species of deuterium and helium. Some specimens were pre-irradiated with $3 \mathrm{keV}-\mathrm{He}^{+}$ions, and then irradiated with 1.5 keV-D $\mathrm{D}^{+}\left(3 \mathrm{keV}-\mathrm{D}_{2}{ }^{+}\right)$ions, which is described as $(\mathrm{He}+\mathrm{D})$ in the following. The other specimens were pre-irradiated with $1.5 \mathrm{keV}-\mathrm{D}^{+}\left(3 \mathrm{keV}-\mathrm{D}_{2}^{+}\right)$ions before irradiation with $3 \mathrm{keV}-\mathrm{He}^{+}$ions, which is described as $(\mathrm{D}+\mathrm{He})$ in the following. The projected range of $3 \mathrm{keV}-\mathrm{He}^{+}$and $1.5 \mathrm{keV}-\mathrm{D}^{+}$ions are quite similar. These irradiations were performed at room temperature and both ion fluxes were about $1 \times 10^{18}$ ions $/ \mathrm{m}^{2} \mathrm{~s}$. The total fluence of the $\mathrm{D}^{+}$ions to all specimens was unified to be $1 \times 10^{21} \mathrm{~m}^{-2}$ for a direct comparison, and the $\mathrm{He}^{+}$ions fluence was varied in the range of $1 \times 10^{21}$ to $1 \times 10^{23} \mathrm{He}^{+} / \mathrm{m}^{2}$.

Some specimens were exposed to a low energy $(\sim 10 \mathrm{eV}) \mathrm{He}^{+}$plasma by using compact plasma-wall interaction (PWI) simulator APSEDAS, installed at Kyushu Univ. [10], prior to the irradiation with $1.5 \mathrm{keV}-\mathrm{D}^{+}\left(3 \mathrm{keV}-\mathrm{D}_{2}^{+}\right)$. The exposure flux of the $\mathrm{He}^{+}$ions was about $1 \times 10^{21}$ $\mathrm{He}^{+} / \mathrm{m}^{2} \mathrm{~s}$, and the total fluence was in the range of $1 \times 10^{23}$ to $1 \times 10^{25} \mathrm{He}^{+} / \mathrm{m}^{2}$.

To investigate the deuterium D retention properties of the irradiated specimens, the TDS of $\mathrm{D}_{2}$ gas was measured while heating the specimen at a constant rate of $1 \mathrm{~K} / \mathrm{s}$ from room temperature to $1473 \mathrm{~K}$, by using a high resolution quadrupole mass spectrometer, which made it possible to 
distinguish masses of helium ions (4.0026 amu) and deuterium ions (4.0282 amu). The $\mathrm{D}_{2}$ signal was quantified with a $\mathrm{D}_{2}$ calibrated leak bottle, and the total amount of $\mathrm{D}$ retained in a specimen was obtained by integrating the TDS signal.

In addition to the TDS measurement, the corresponding microstructure evolution induced by the irradiation with $3 \mathrm{keV}-\mathrm{He}^{+}$or $1.5 \mathrm{keV}-\mathrm{D}^{+}\left(3 \mathrm{keV}-\mathrm{D}_{2}{ }^{+}\right)$was also examined using an in-situ transmission electron microscope (TEM) equipped with an ion gun..

\section{Result and discussion}

\subsection{Effects of sequential irradiation}

To investigate retention properties of deuterium atoms, TDS was performed after a sequential irradiation of the specimen. Fig. 1 compares the desorption spectra of deuterium gas from the specimens irradiated with $3 \mathrm{keV}-\mathrm{He}^{+}$and $1.5 \mathrm{keV}-\mathrm{D}^{+}$; (He+D), $1.5 \mathrm{keV}-\mathrm{D}^{+}$and $3 \mathrm{keV}-\mathrm{He}^{+}$; (D+He), and only $\mathrm{D}^{+}$ions to a respective fluence of $1.0 \times 10^{21} \mathrm{ions} / \mathrm{m}^{2}$ at room temperature. It is seen that desorption of deuterium gas from $(\mathrm{He}+\mathrm{D})$ specimen continues over a wide temperature range from

$380 \mathrm{~K}$ to about $850 \mathrm{~K}$, peaking at about $510 \mathrm{~K}$. The retained amount was about $2.5 \times 10^{20} \mathrm{D} / \mathrm{m}^{2}$, which was much greater than the other specimens. In the specimen irradiated with only $\mathrm{D}^{+}$ions, the desorption also starts at about $380 \mathrm{~K}$, peaking at about $440 \mathrm{~K}$; however, the retained amount of deuterium gas was very small, about $3,0 \times 10^{19} \mathrm{D} / \mathrm{m}^{2}$. In the $(\mathrm{D}+\mathrm{He})$ specimen, the retained amount was about $1.3 \times 10^{19} \mathrm{D} / \mathrm{m}^{2}$, which started to desorb at $620 \mathrm{~K}$, peaking at about $700 \mathrm{~K}$.

These results suggest that the significant difference in the retention properties between the $(\mathrm{He}+\mathrm{D})$ and $(\mathrm{D}+\mathrm{He})$ specimens is caused by differences in the microstructures of the specimens. Fig. 2compares the electron micrographs of the specimens irradiated with $1.5 \mathrm{keV}-\mathrm{D}^{+}$ions or $3 \mathrm{keV}-\mathrm{He}^{+}$ ions to a fluence of $1 \times 10^{21}$ ions $/ \mathrm{m}^{2}$ at room temperature. In this figure, dislocation loops are seen as black featured images due to strain fields, and He bubbles with circular white contrasts are seen for the specimens irradiated with high fluence of $3 \mathrm{keV}-\mathrm{He}^{+}$ions. It is seen that only small dislocation loops were formed in the specimen irradiated with $\mathrm{D}^{+}$ions, while in the specimen irradiated with $\mathrm{He}^{+}$ ions, high densities of dislocation loops and bubbles were formed. The difference in the 
microstructure can not be explained by a difference in the amount of the displacement damage and likely comes from a strong interaction of vacancies with helium atoms, in comparison with deuterium atoms, as reported elsewhere [11,12].

The results of the TDS and the microstructure observation described above suggest that the dislocation loops and bubbles in W play an important role of the trapping sites for deuterium. In the $(\mathrm{He}+\mathrm{D})$ specimen, dislocation loops and bubbles in high density, formed by $\mathrm{He}^{+}$irradiation, caused the broad TDS spectrum over the wide temperature range as seen in Fig. 1. We can infer that the strength of dislocation loops as trapping sites for deuterium is weaker than that of bubbles, which affects the starting temperature of the evolution. In the $(\mathrm{D}+\mathrm{He})$ specimen, deuterium atoms trapped at dislocation loops formed by pre- $\mathrm{D}^{+}$irradiation may be released during the subsequent $\mathrm{He}^{+}$ irradiation by some kinds of irradiation effects, such as the growth of interstitial type dislocation loops and other excitation effects. Some of the deuterium atoms released from the dislocation loops could be trapped by bubbles formed by the subsequent $\mathrm{He}^{+}$irradiation, which causes the small TDS peak, desorbing at a higher temperature above $620 \mathrm{~K}$.

\subsection{Effects of the fluence of pre-irradiated He on D-TDS}

To examine more details of the pre-irradiation effects of $\mathrm{He}^{+}$ions on deuterium retention, we changed the fluence of the pre-irradiation of $\mathrm{He}^{+}$ions. Fig. 3 shows the deuterium TDS spectra of the specimens irradiated with $1.5 \mathrm{keV}-\mathrm{D}^{+}$ions after the irradiation of $\mathrm{He}^{+}$ions to fluences in the range of $1.0 \times 10^{21}$ to $1.0 \times 10^{23} \mathrm{He}^{+} / \mathrm{m}^{2}$. As seen from the figure, with the increase of the fluence from $1.0 \times 10^{21}$ to $1.0 \times 10^{22} \mathrm{He}^{+} / \mathrm{m}^{2}$, the retained amount of deuterium increased. This increase is probably due to the increase of trapping sites, as discussed in the previous section, introduced by the $\mathrm{He}^{+}$ irradiation. Simultaneously, the peak temperature shifts from $520 \mathrm{~K}$ to $420 \mathrm{~K}$, which may be caused by a start of interconnection between bubbles due to the increase of the bubble density. In the specimen irradiated to $1.0 \times 10^{23} \mathrm{He}^{+} / \mathrm{m}^{2}$, the interconnected structure between bubbles is suggested to grow over a significant amount of bubbles, which means the formation of easy diffusion path of deuterium to the specimen surface and significantly decreases the retained amount of deuterium. 
Information on the large decrease in deuterium retention in $\mathrm{W}$ with the increase of helium irradiation is very important in the plasma operation under DT burning. Therefore, in the following, the exposure effect of helium plasma with very low energy is studied.

\subsection{Effects of pre-exposure of helium plasma on D-TDS}

Some specimens were pre-exposed to very low energy $(\sim 10 \mathrm{eV})$ helium plasma before being irradiation with deuterium ions. In the present experiment, He-induced nano-structures (fuzz or tendril) were not observed on surfaces exposed to He plasmas. This is because the specimen temperature during the plasma exposures is well below $1000 \mathrm{~K}$. Fig. 4 shows the TDS of deuterium from the specimens irradiated with $1.5 \mathrm{keV}-\mathrm{D}^{+}$ions after the pre-exposure of helium plasma to fluences of $1 \times 10^{23}-1 \times 10^{25}$ ions $/ \mathrm{m}^{2}$ by using APSEDAS at room temperature. It is seen that the retention of $\mathrm{D}$ is very low in comparison with the irradiation of $3 \mathrm{keV}-\mathrm{He}^{+}$shown in Fig. 3. In addition, with the increase of the He plasma exposed, the D retention decreases greatly.

In the He plasma pre-exposure case, the $\mathrm{He}^{+}$ion range is significantly lower than the 1.5 $\mathrm{keV}-\mathrm{D}^{+}$ions. Injected $\mathrm{He}^{+}$ions can easily diffuse due to their high mobility through interstitial sites, and the distribution of He bubbles seems to be shifted toward the bulk much deeper than the injected range. As we have already reported in [9], linked bubbles have been observed in a cross-sectional view of $\mathrm{W}$ by TEM, which was exposed to low energy $\mathrm{D}+\mathrm{He}$ mixture plasma to a fluence of $\sim 5 \times 10^{25}$ ions $/ \mathrm{m}^{2}$ at $573 \mathrm{~K}$. The linked bubbles were located at a depth from the specimen surface to several tens $\mathrm{nm}$. Therefore, we infer that a similar linked bubble structure was also formed in the present case and the degree of the linkage increased with the increase of the plasma fluence. Thus linked or interconnected bubbles are suggested to play a role in the easy release and diffusion path for deuterium atoms, resulting in a reduction in deuterium retention.

\section{Summary}

To investigate the effects of helium irradiation on deuterium retention properties in $\mathrm{W}$, the TDS of deuterium from a specimen irradiated with a sequential irradiation of $3 \mathrm{keV}$ helium and 1.5 $\mathrm{keV}$ deuterium ions at room temperature were measured. 
The main results are summarized as follows.

(1) Pre-irradiation using $3 \mathrm{keV}-\mathrm{He}^{+}$ions to fluences of $1.0 \times 10^{21}-1.0 \times 10^{22} \mathrm{He}^{+} / \mathrm{m}^{2}$ resulted in an increase of deuterium retention (the deuterium was implanted after the $\mathrm{He}^{+}$irradiation), shifting the desorption peak to lower temperatures with the increase of the $\mathrm{He}^{+}$fluence.

(2) The retention of deuterium was drastically decreased above a fluence of $1.0 \times 10^{23} \mathrm{He}^{+} / \mathrm{m}^{2}$, which was pre-irradiated.

(3) A similar reduction of deuterium retention was also observed in the specimen exposed to a very low energy helium plasma $(\sim 10 \mathrm{eV})$ in APSEDAS to fluences of $1 \times 10^{23}-1 \times 10^{25} \mathrm{ions} / \mathrm{m}^{2}$ prior to deuterium irradiation.

(4) The TDS spectra of deuterium and microscopic observation suggested that dislocation loops and bubbles play a role of trapping sites for deuterium. The trapping strength of the bubble is much stronger than that of the dislocation loop.

(5) The reduction of deuterium retention with the increase of pre- irradiation of helium ions was considered to be due to the formation of linked or interconnected structure of bubbles, which could act as a diffusion path to the surface for deuterium atoms.

(6) Post-irradiation using helium ions causes a reduction of deuterium retention. Easy release of the deuterium trapped at dislocation loops formed by pre-irradiation using deuterium may be caused during post-irradiation with helium. 


\section{References}

[1] A. Loarte et al., Nuclear Fusion 47(2007)S203.

[2] H. T. Lee et al., J. Nucl. Mater. 363-365(2007)898.

[3] Y. Ueda et al., J. Nucl. Mater. 386-388(2008) 725.

[4] H. Iwakiri, K. Morishita, N. Yoshida, J. Nucl. Mater 307-311 (2002) 135-138

[5] D. Nishijima et al., Nucl. Fusion 45(2005)669.

[6] M. J. Baldwin et al., J. Nucl. Mater. 390-391 (2009) 886-890

[7] M. Miyamoto et al., Nucl. Fusion 49(2009)065035.

[8] V. Kh. Alimov et al., Phys. Scripta T138(2009)014048.

[9] M. Miyamoto et al., J. Nucl. Mater, J. Nucl. Mater (2011). doi: 10/1016/j.jnucmat.2011.01.008

[10] M. Sakamoto et al. Phyca Scripta, T138 (2009) 014043

[11] N. Yoshida et al. J. Nucl. Mater. 337-339 (2005) 946

[12] K. Arakawa et al. J. Nucl. Mater. 307-311 (2002) 272-277 
Fig. 1. one-column, Y. Sakoi

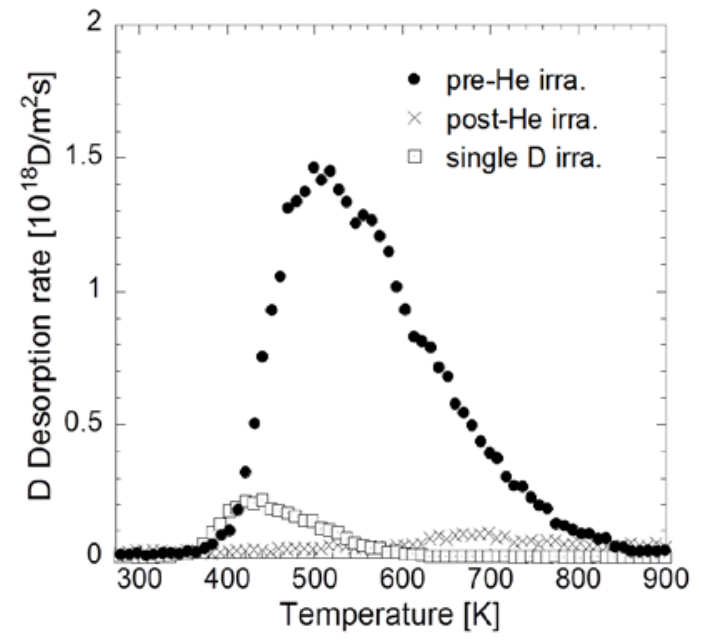

Fig. 1. Thermal desorption spectra of deuterium gas atoms from the specimens irradiated with $(\bullet)$ :

(He+D), $(\times)$ : $(\mathrm{D}+\mathrm{He})$, and $(\square)$ : only deuterium ions at room temperatures. The heating rate was $1 \mathrm{~K} / \mathrm{s}$. 
Fig. 2 two-column, Y. Sakoi

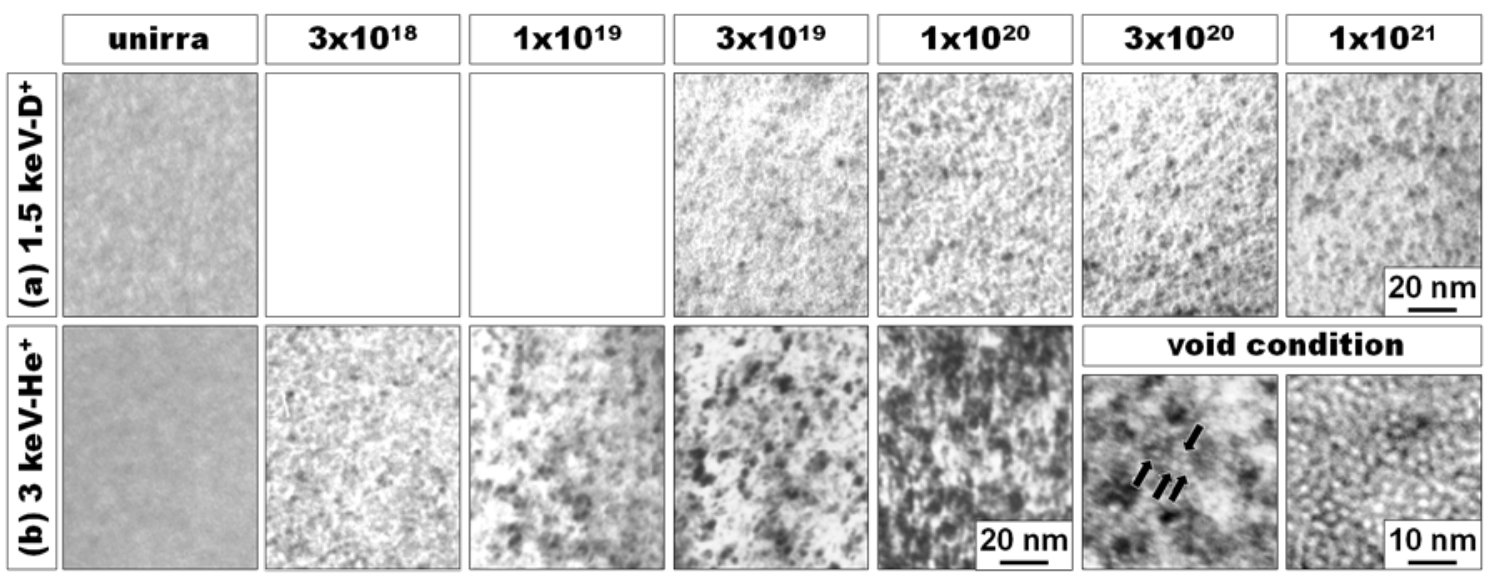

Fig. 2. Electron micrographs of the specimens irradiated with $1.5 \mathrm{keV} \mathrm{D}^{+}$ions to a fluence of $1 \times 10^{21}$

$\mathrm{D}^{+} / \mathrm{m}^{2}$ (upper graphs), and with $3 \mathrm{keV} \mathrm{He}^{+}$ions to a fluence of $1 \times 10^{21} \mathrm{He}^{+} / \mathrm{m}^{2}$ at room temperature (lower graphs). 
Fig. 3 one-column, Y. Sakoi

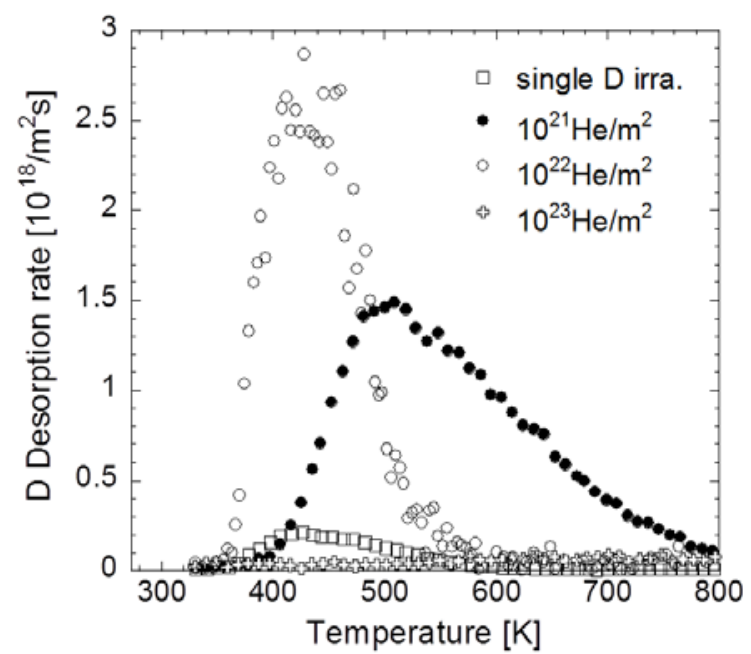

Fig. 3. Deuterium TDS spectra of the specimens post-irradiated with $1.5 \mathrm{keV} \mathrm{D}^{+}$ions to a fluence of $1 \times 10^{21} \mathrm{D}^{+} / \mathrm{m}^{2}$ after the pre-irradiation of $3 \mathrm{keV} \mathrm{He}$ ions to fluences of $(\bullet): 1 \times 10^{21} \mathrm{He}^{+} / \mathrm{m}^{2}$, (०): $1 \times 10^{22} \mathrm{He}^{+} / \mathrm{m}^{2},(+): 1 \times 10^{23} \mathrm{He}^{+} / \mathrm{m}^{2}$, and (口): only $\mathrm{D}^{+}$ions, respectively, at room temperature. 
Fig. 4 one-column, Y. Sakoi

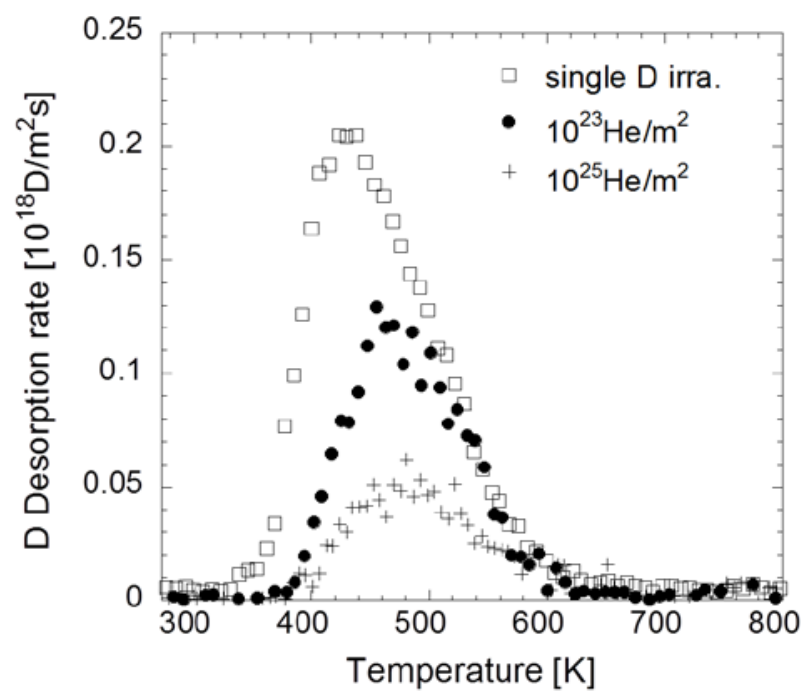

Fig. 4. Deuterium TDS spectra of the specimens irradiated with $1.5 \mathrm{keV} \mathrm{D^{+ }}$ ions to a fluence of $1 \times 10^{21} \mathrm{D}^{+} / \mathrm{m}^{2}$ after the pre-exposure of $\sim 10 \mathrm{eV} \mathrm{He} \mathrm{H}^{+}$plasma to fluences of $(\bullet): 1 \times 10^{23} \mathrm{He}^{+} / \mathrm{m}^{2}$, (+): $1 \times 10^{25} \mathrm{He}^{+} / \mathrm{m}^{2}$, and ( $\square$ ): only $\mathrm{D}^{+}$ions, respectively, at room temperature. 